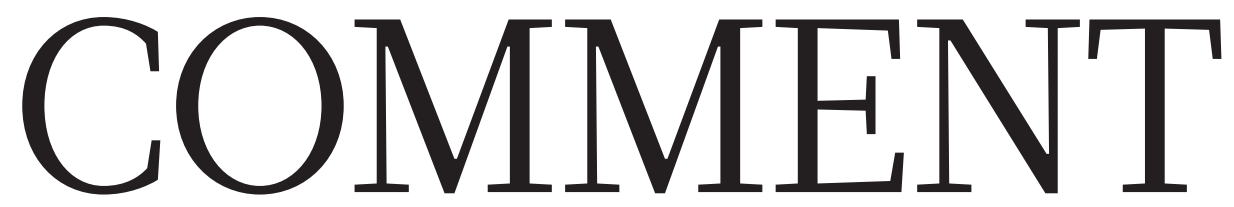

ASTRONOMY How the transit of Venus could help to detect other worlds p.303
ANATOMY The nutrients and toxins found in human breast milk p.306 sound Bernie Krause on the acoustics of ecosystems p.308
SUSTAINABILITY India needs better management of electronic waste $\mathbf{p . 3 0 9}$

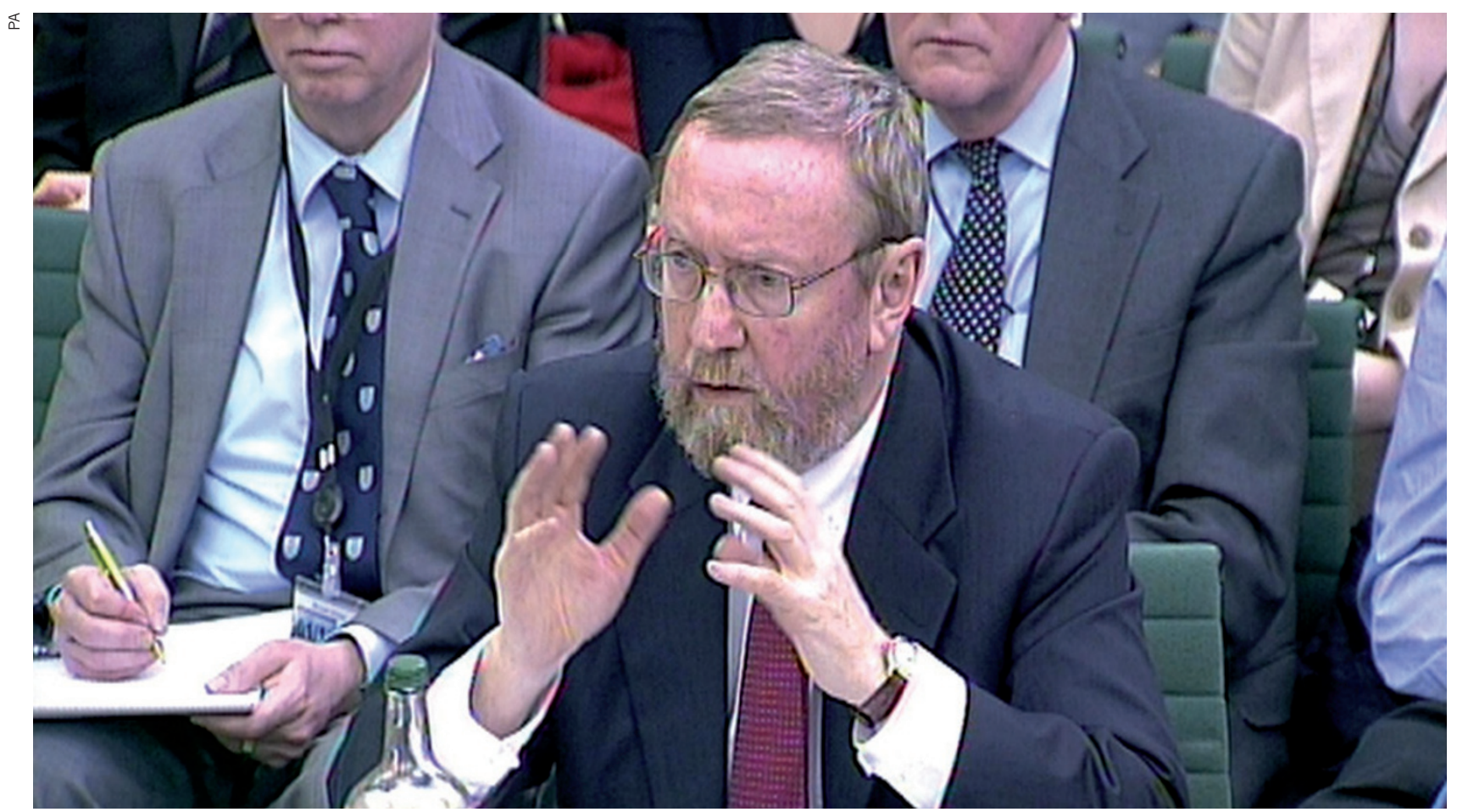

The UK chief scientific adviser, John Beddington, has overseen the installation of science advisers in every department of the British government.

\title{
Beyond the great and good
}

Chief scientific advisers need better support and networks to ensure that science advice to governments is robust, say Robert Doubleday and James Wilsdon.

\begin{abstract}
A $s$ the UK government's chief scientific adviser contemplates the end of his term of office this December, he could be forgiven a smile of satisfaction. During his five years in the post, John Beddington, a population biologist, has navigated the 2009 swine-flu outbreak and the volcanic ash cloud in 2010, limited the damage from controversies over climate science and drugs policy, and defined his own priorities - notably, his concept of a 'perfect storm' of insecurity over food, energy and water. He has also presided over the spread of 22 departmental chief scientific advisers (CSAs) into every corner of the British government, even Her Majesty's Treasury, where economics alone has traditionally held sway.

Beddington's legacy extends farther afield
\end{abstract}

as a result of the international support he has built for the CSA concept. Equivalent posts have been created in New Zealand and at the European Commission in the past few years, and are proposed in Japan and at the United Nations. For those in the scientific community who have long advocated better structures for policy advice, this enthusiasm for CSAs is encouraging. But, as recruitment of Beddington's successor begins, and with similar job descriptions being rolled out elsewhere, it is timely to reflect on the strengths and weaknesses of this model.

There is no universal solution to science advice. The CSA concept has been shaped by a particularly British

\section{DNATURE.COM}

C. P. Snow's portrait of science in politics: go.nature.com/gxskb5 approach to expertise, which focuses on the credibility and character of the individual. The UK model is working well. But it has its tensions, and may not transplant easily.

A focus on the personal standing of the CSA, as in the United Kingdom, needs to be balanced by greater attention to the mix of skills, structures and staff required for highquality policy advice. There needs to be a more open discussion by policy-makers of the trade-offs between independence and influence, and of the weight given to different disciplines and perspectives within the advisory system. Governments should do more to incorporate insight from the growing body of scholarship on science policy and expert advice. There is a need for international networks that enable science 
advisers from different countries to learn from one another.

The United Kingdom has had a crossgovernment chief scientific adviser since zoologist Solly Zuckerman's appointment in 1964. The adviser is a point of connection between science, politics and public policy: their role is to act as a personal adviser to the prime minister and the Cabinet, to lead the Government Office for Science, and to speak to the public and the media.

The US equivalent, the presidential scientific adviser, has evolved in parallel, and advisory systems from Australia and India to Ireland and Malaysia have blended elements of both models. Whereas the presidential scientific adviser serves the White House, the UK equivalent has a broad purview across all government departments. This distinction has sharpened as each department has appointed its own CSA, a process that began in 2002 in response to perceived failings in policy advice during the mid-1990s BSE crisis. By contrast, the reliance on hundreds of expert committees across the US political system has, in effect, restricted the remit of the presidential scientific adviser ${ }^{1}$.

\section{INFLUENTIAL MODEL}

The UK model is increasingly seen as a template elsewhere. Medical scientist Peter Gluckman, appointed in 2009 as New Zealand's first CSA, plans to install scientific advisers in a number of the country's ministries. In December 2011, José Manuel Barroso, president of the European Commission, announced molecular biologist Anne Glover, former CSA to the Scottish government, as Europe's first CSA.

In Japan, the government has set out plans to install chief science advisers to the prime minister and other ministers, as part of an overhaul of the science advisory system proposed after last year's earthquake, tsunami and nuclear disaster. At the United Nations in New York, Secretary-General Ban Ki-moon announced in April that he will appoint a CSA as part of a package of reforms designed to strengthen the international governance of sustainable development, recommended ahead of the Rio+20 summit in June 2012 (ref. 2).

With so many nations adopting the CSA model, it is worth noting that the system is a product of one political culture. For example, a 2012 report by the UK House of Lords Science and Technology Committee highlighted "standing and authority within the scientific community" as the foremost essential characteristic of a CSA ${ }^{3}$. Therefore, they should be externally appointed senior figures, drawn from academia or industry, who can access a wide range of expertise by dint of their position and reputation.

These recommendations sit comfortably within Britain's political culture, which has long emphasized the authority of individual experts with a track record of public service. But there is more to effective science policy than being one of the great and good. Even though most UK CSAs would pass the Lords' 'scientific standing' criterion with flying colours, the report acknowledges the uneven performance of some. The variable budgets across different departments may be partly responsible. The Lords recommend increasing the CSA's status, autonomy and funding, but other factors deserve attention, such as how CSAs fit within wider policy-making structures.

"The theory
and analysis
of scientific
advice needs
to better
inform its
practice."

The report lists other qualities that CSAs should have: an ability to engage with stakeholders; to manage multidisciplinary teams; to understand the policy environment; and to be able to evaluate conflicting evidence from a range of perspectives. However, these are listed as only secondary considerations.

Linked to this is the vexed question of whose expertise counts. As its network of CSAs has grown, the United Kingdom has drawn advisers from across the natural sciences, and recently engineering, economics and social science. The Lords' report calls for a new post of chief social-science adviser to provide a better conduit for advice from that community. But creating stand-alone structures for different disciplines is a clumsy solution. The issue is how to integrate an appropriate mix of expert advice across government to address inherently interdisciplinary issues - from climate change to food security and obesity.

\section{GLOBAL LESSONS}

So what lessons can other countries draw from the UK system? First, although a focus on the credentials and character of individual CSAs is important, it needs to be balanced with the mix of skills, structures and staff that is essential for high-quality scientific advice. Science-policy expert Roger Pielke Jr has argued that it is a mistake to base advisory systems on the idea of a CSA as "a heroic individual with special influence on policy making" (see go.nature. com/broi9t). Neither should CSAs be seen as a 'one-way membrane' that allows science into politics while protecting science from political influence; governments need to create processes for integrating the two.

Second, there needs to be greater recognition of the contribution that different disciplines and perspectives make to an effective advisory system - including the social sciences, arts and humanities, but also civil society and the public. James Killian, for example, who advised US President Dwight D.
Eisenhower and was widely regarded as the most successful US science adviser, was not a scientist and had a degree in management.

Advisory systems must acknowledge the importance of politics in shaping what counts as evidence and authority, as well as the plural, conditional nature of knowledge. As noted by Andy Stirling, a science-policy researcher at the University of Sussex in Brighton, UK, expert advice is often expected to provide one interpretation and to reduce uncertainties to measurable risks. However, this process of 'closing down' limits the scope of advice ${ }^{4}$.

Third, the theory and analysis of scientific advice needs to better inform its practice. There is now a wealth of empirical research into how advisory processes operate; a recent exercise led by the Centre for Science and Policy at the University of Cambridge, UK, sought to identify the most pressing questions about the relationship between science and policy ${ }^{5}$. Sheila Jasanoff, professor of science and technology studies at Harvard Kennedy School of Government in Cambridge, Massachusetts, argues that "good science in public decision-making cannot be divorced from deeper reflection on the ways in which democracies should reason" ${ }^{\text {. We think that }}$ CSAs would benefit from processes of learning and reflection that are more systematic.

Finally, stronger international networks are required for CSAs to exchange ideas. The main forum is currently the Carnegie Group of Science Advisers, which was established in 1991 to enable CSAs and science ministers from the G8 nations to meet annually, and which has recently expanded to include Brazil, China, India, Mexico and South Africa. A more open global network is now required. In a welcome step towards this goal, the CSA of Quebec recently invited all CSAs to a meeting in Montreal in October 2012.

The learning needs to flow in all directions. As the process for appointing Beddington's successor gets under way, these lessons should be applied in London, too.

Robert Doubleday is head of research at the Centre for Science and Policy, University of Cambridge, UK. James Wilsdon is professor of science and democracy at the Science Policy Research Unit, University of Sussex, Brighton, UK.

e-mail:j.wilsdon@sussex.ac.uk

1. Pielke Jr, R. \& Klein, R. A. (eds) Presidential Science Advisors (Springer, 2010).

2. United Nations Secretary-General's High-Level Panel on Global Sustainability Resilient People, Resilient Planet: A Future Worth Choosing (United Nations, 2012).

3. House of Lords Select Committee on Science and Technology The Role And Functions Of Departmental Chief Scientific Advisers (The Stationery Office, 2012).

4. Stirling, A. Nature 468, 1029-1031 (2010)

5. Sutherland, W. J. et al. PLoS ONE 7, e31824 (2012).

6. Jasanoff, S. In The Politics of Scientific Advice (eds Lentsch, J. \& Weingart, P.) Part I, Ch. 2 (Cambridge University Press, 2011). 